EGU21-8174, updated on 10 Feb 2022

https://doi.org/10.5194/egusphere-egu21-8174

EGU General Assembly 2021

(c) Author(s) 2022. This work is distributed under

the Creative Commons Attribution 4.0 License.

\title{
Frictional behaviour of carbonate bearing faults at brittle-ductile transition
}

Francesco Figura, Carolina Giorgetti, Mathias Lebihain, and Marie Violay

EPFL, ENAC, LEMR, Switzerland (francesco.figura@epfl.ch)

One of the most alarming recent findings in geo-science is the dramatic rise in the rate of humaninduced earthquakes in the past decade. This is due to the fluid injection or extraction in deep reservoirs for hydrocarbon production, wastewater and $\mathrm{CO}_{2}$ storage and exploitation of geothermal resources which result in the reactivation of nearby faults. These reservoirs are often located 2-3 km depth (i.e. $30 \mathrm{MPa}$ ), and are hosted in or covered by sedimentary carbonate layers. As carbonate undergoes a brittle-ductile transition with increasing confining pressure from values of around $20 \mathrm{MPa}$, ductile deformation can play an important role on the nucleation and propagation of earthquakes on carbonate faults. Here, we investigate the role of increasing ductile behaviour on fault frictional parameters. The research is performed through the new biaxial apparatus installed at EPFL, the HighSTEPS (High Strain TEmperature Pressure Speed) apparatus, able to measure frictional parameters in a wide range of shearing velocities $\left(10^{-6} \mathrm{~m} / \mathrm{s}-0.2 \mathrm{~m} / \mathrm{s}\right)$ and under unique boundary conditions representative of the Earth's crust, i.e., normal stress up to $100 \mathrm{MPa}$, confining pressure up to $100 \mathrm{MPa}$, pore fluid pressure up to $100 \mathrm{MPa}$ and temperature up to $120^{\circ}$. The induced stress state in bare surface samples was previously studied by a comparison between results of FEM numerical analyses and experimental ones. Under shear loading conditions, the principal stress $\sigma 1$ is oriented at about $25^{\circ}$ to the vertical axis, and the confining pressure corresponds to the principal stress $\sigma 2$. Tests are performed under different values of applied confining pressure $(1-60 \mathrm{MPa})$ and normal stress $(1.5-90 \mathrm{MPa})$ on the faults, keeping constant the ratio between $\sigma \mathrm{n} / \sigma 3$ around $\sim 3$, to mimic faults at different depth. We present experimental results mapping carbonate fault mechanical behaviour from low shearing velocity $10^{-6} \mathrm{~m} / \mathrm{s}$ to high shearing velocity $10^{-1} \mathrm{~m} / \mathrm{s}$. Moreover, experimental results are modelled with rate-and-state friction laws (RSFLs) to define rate and state parameters related to the critical conditions for fault stability and its dependence on the presence of ductile deformation. These results shed new light on the nucleation and propagation of earthquake within the brittle-ductile transition in carbonate bearing rocks. 